\title{
Rudolf Kraus em busca do "ouro da ciência": a diversidade tropical e a elaboração de novas terapêuticas, 1913-1923
}

\section{Rudolf Kraus in search of the "gold of science": tropical diversity and the development of new treatments, 1913-1923}

\author{
Juliana Manzoni Cavalcanti \\ Doutoranda do Programa de Pós-graduação em \\ História das Ciências e da Saúde/Casa de Oswaldo Cruz/Fiocruz. \\ Av. Brasil, 4306/4 andar \\ 21040-361 - Rio de Janeiro - RJ - Brasil \\ jujumanzoni@yahoo.com.br
}

CAVALCANTI, Juliana Manzoni. Rudolf Kraus em busca do "ouro da ciência": a diversidade tropical e a elaboração de novas terapêuticas, 1913-1923. História, Ciências, Saúde - Manguinhos, Rio de Janeiro, v.20, n.1, jan.-mar. 2013, p.221-237.

\section{Resumo}

Com base na trajetória de Rudolf Kraus, o artigo analisa a busca de curas para doenças infecciosas em regiões tropicais no início do século XX, dando especial atenção à elaboração por Kraus de novos terapêuticos biológicos como soros, vacinas e soluções proteicas. As regiões tropicais eram com frequência apresentadas como mais propícias à pesquisa devido à maior quantidade de organismos a identificar e também à concorrência supostamente menor entre pares. Os trópicos eram, assim, considerados um oásis para as pesquisas microbiológicas. Kraus dedicou-se à fabricação de diversos produtos de origem biológica, mas não teve o sucesso esperado com muitos deles.

Palavras-chave: Rudolf Kraus (18681932); diversidade tropical; América do Sul; história da microbiologia; história de soros e vacinas.

\section{Abstract}

Based on the career of Rudolf Kraus, the article analyzes the search for cures to infectious diseases in tropical regions in the early twentieth century, focusing especially on Kraus' development of new biological treatments like sera, vaccines, and protein solutions. At that time, the world's tropical regions were often portrayed as more propitious for research, given the larger number of organisms that could be identified in these realms and an allegedly lower level of peer competition as well. The tropics were thus seen as an oasis for microbiological research. Kraus dedicated himself to the production of various products of biological origin, but he failed to achieve his hoped-for success with many of them.

Keywords: Rudolf Kraus (1868-1932); tropical diversity; South America; history of microbiology; history of sera and vaccines. 
$\mathrm{E}$ ste trabalho analisa parte da trajetória científica de Rudolf Kraus (1868-1932) procurando ilustrar como, nas primeiras três décadas do século XX, cientistas elaboravam, de forma desenfreada, terapêuticos para curar as mais diversas doenças infecciosas. A trajetória desse microbiologista e imunologista mostra que a busca de novos produtos parecia ser mais proveitosa nos trópicos, pois foi aí que ele elaborou todos os produtos de sua carreira científica. A perspectiva de identificar microrganismos patogênicos e vetores de doenças nos trópicos atraiu muitos cientistas europeus para a América do Sul entre o último quartel do século XIX e os primeiros trinta anos do XX. As técnicas de produção de vacinas e soros então disponíveis mostravam-se promissoras ao desenvolvimento de terapêuticos para as mais diversas doenças. O êxito nesse esforço prometia trazer aos cientistas reconhecimento e renome internacionais, além de lucros com a venda do produto em questão.

As relações da bacteriologia, medicina tropical, parasitologia e imunologia, com a indústria e o comércio já estavam estabelecidas quando Rudolf Kraus aportou em Buenos Aires, em 1913. Tais relações poderiam traduzir-se em estreita parceria entre uma empresa e um cientista, como foi, por exemplo, o caso de Robert Koch e Ersnt Abbe no desenvolvimento da firma Zeiss Optik, que hoje ainda fabrica microscópios; ou o de Emil von Behring e a empresa farmacêutica Hoechst na fabricação do soro antidiftérico (Sarasin et al., 2007; Throm, 1995). Havia também a possibilidade de vender produtos terapêuticos elaborados individualmente, por intermédio de representantes ou empresas farmacêuticas, como, por exemplo, a vacina contra o carbúnculo desenvolvida por Pasteur, Chamberland e Roux, e vendida por La Compagnie de Vulgarisation du Vaccin Charbonneux Pasteur (Cassier, 2005, p.733).

Diversos microrganismos e vetores de doenças vinham sendo identificados nos trópicos e figuravam entre as descobertas mais importantes para a sedimentação da microbiologia em geral. Exemplos de microrganismos identificados nas regiões ditas tropicais foram: o bacilo do cólera em 1884 por Robert Koch na Índia; o bacilo da peste em 1894 por Shibasaburo Kitasato e Alexandre Yersin em Hong Kong; o tripanossoma da doença do sono em 19021903 em Uganda; e o Trypanosoma cruzi em 1909 por Carlos Chagas no Brasil. Muitos vetores e mecanismos de transmissão foram também identificados nos trópicos: a transmissão da filariose pelo mosquito e, depois, a da malária e da febre amarela. Os trópicos representavam, portanto, um oásis de doenças, vetores e microrganismos para os cientistas que buscavam destacar-se mediante descobertas científicas.

O depoimento do cientista italiano Antonio Carini (citado em Teixeira, 1994, p.80) retrata de forma clara as possibilidades de êxito nos trópicos.

Para bem compreender o entusiasmo com que aceitei o convite para vir para o Brasil, é preciso transportar-se com o pensamento àqueles tempos. Entre o fim do século passado e o início do atual, a microbiologia estava no seu auge, passando de sucesso em sucesso, revolucionando a medicina e parecia destinada a esclarecer a etiologia de todas as doenças e encontrar todos os soros e as vacinas para combatê-las ... Os pesquisadores que tinham ido aos países tropicais encontravam abundante material de estudos e voltavam cheios de louros ... É, pois, de estranhar se naquela atmosfera deixei sem hesitar o afamado instituto de Berna para vir para o Brasil?

Em 1905, Carini chegou ao Brasil convidado para dirigir o Instituto Pasteur de São Paulo, que fabricava soros e vacinas de uso humano e animal. O instituto paulista recebia subsídios 
estatais, mas a maior parte de sua renda era auferida com a comercialização dos produtos. Além do reconhecimento e renome que poderia alcançar, a elaboração de um novo terapêutico também poderia ser fonte de lucros. Como mostra o relato do cientista, a microbiologia estava no auge no início do século XX. As descobertas e os fatos advindos da nova ciência dos micróbios ressoavam tanto nos meios científicos como nos não científicos. As exposições de higiene e as que retratavam epidemias exerciam forte apelo junto ao público leigo, como as que ocorreram em 1903 e 1911 na cidade de Dresden, na Alemanha (Berger, 2009, p.79). Os microbiologistas de então se achavam em momento de grandes expectativas alimentadas por vários setores da sociedade e de amplas possibilidades de pesquisa.

É de frisar, no entanto, que o desejo de se deslocar para terras longínquas muitas vezes estava associado a sentimentos negativos em relação à situação ou às condições de trabalho nos países de origem desses cientistas. Novamente, a trajetória de Robert Koch serve de ilustração. A partir da década de 1890, quando surgiram as primeiras críticas à tuberculina e, concomitantemente, a volta da questão da hereditariedade na tuberculose, que Koch acreditara ter afastado, suas viagens de pesquisas passariam a ser mais frequentes (Gradmann, 2005, p.258).

O esclarecimento da etiologia da tuberculose e do cólera, na época muito em evidência na Europa, havia posto Koch no topo da ciência no último quartel do século XIX. Uma das consequências desse sucesso foi o apoio ao desenvolvimento da bacteriologia mediante a criação de institutos e publicações, o que deu ensejo, por sua vez, ao aumento do número de colegas e concorrentes. Nesse período, também se observa crescente especialização com o surgimento de outros campos, como, por exemplo, a imunologia, a parasitologia, a sorologia e a medicina tropical que, apesar de interligadas com a bacteriologia, acabaram por tornar-se áreas de pesquisa independentes. A especialização não foi bem vista por Koch, que se sentiu acuado pela crescente concorrência de outros cientistas que passavam a dominar técnicas por ele desconhecidas (Gradmann, 2005, p.258). A citação a seguir, retirada de carta escrita quando estava na Rodésia pesquisando a peste bovina, ilustra a convergência entre o desejo de viajar e as condições de trabalho que ele tinha nos trópicos e em seu país de origem: "Entre nós [na Alemanha] já foi tudo tão profundamente trabalhado, e a concorrência é tão violenta, que realmente não vale mais a pena pesquisar aí. Aqui no exterior, no entanto, ainda está disponível o 'Ouro da Ciência'. Quanta novidade eu vi e aprendi desde que vim pela primeira vez para a África” (Gradmann, 2005, p.254; destaque meu). ${ }^{1}$

Além das particularidades de Koch, há que salientar a própria conformação da bacteriologia como disciplina de experimentação em locais externos ao laboratório. Desse modo, ao tratar da biografia ou trajetória profissional de um cientista devem-se levar em conta não apenas as preferências e conjunturas pessoais, mas o desenvolvimento de seu campo de atuação (Gradmann, 2005, p.255, 264). ${ }^{2}$ A bacteriologia era então aliada das pretensões colonialistas europeias devido à necessidade de se lidar com doenças ainda desconhecidas ou endêmicas nas regiões tropicais. A disseminação dos institutos Pasteur por territórios coloniais e outros países é um dos exemplos clássicos dessa expansão dos bacteriologistas europeus para essas regiões e mostra como os interesses coloniais se coadunaram aos dessa disciplina (Moulin, 1992, p.307-308). 
Os trópicos realmente ofereciam novas oportunidades, fosse pela maior diversidade natural e, portanto, maior variedade de doenças, fosse pela facilidade de realizar pesquisas devido a uma suposta menor concorrência. A partir da década de 1890, a imunologia começava a surgir como disciplina independente, constituindo-se de muitos debates teóricos e de suas aplicações práticas. A experimentação de terapêuticos de origem biológica, isto é, a imunização em geral era um dos temas caros da disciplina. Com isso, as oportunidades de pesquisa oferecidas nos trópicos também se estendiam a essa área. Para Kraus, além da perspectiva de sucesso nas pesquisas, a ida para os trópicos representou uma tentativa de crescer profissionalmente, pois em Viena sua carreira chegara a um limite, com o esgotamento de suas possibilidades de ascensão.

\section{Os anos antes da viagem à América do Sul}

Rudolf Kraus nasceu em 30 de outubro de 1868, em Mladá Boleslav, na Boêmia, atual República Tcheca. Formou-se em medicina pela Universidade Alemã de Praga, em 1893. No ano seguinte, foi para Viena a fim de trabalhar na clínica do professor Edmund Neusser (1852-1912) e depois seguiu para o Instituto Pasteur de Paris, onde permaneceu durante alguns meses de 1895. Foi convidado então para trabalhar no recém-fundado Staatliches Serotherapeutisches Institut Wien (Instituto Soroterápico Federal de Viena), sob a direção de Richard Paltauf. Nesse instituto, em que ingressou em 1896, logo se destacaria nos estudos sobre as reações sorológicas e imunizações. Em 1903, Kraus trabalhou na estação zoológica de Rovigno, com Fritz Schaudinn, e com Constantini Levaditi no Instituto Pasteur de Paris; dois anos depois fez o curso de protozoologia no Institut für Schiffs- und Tropenkrankheiten (Instituto de Doenças Marítimas e Tropicais de Hamburgo). Tornou-se Privatdozent, em 1906, da cátedra de patologia geral e experimental (Allgemeine und Experimentelle Pathologie) na Universidade de Viena, na qual ministrava aulas de imunologia, soroterapia, doenças infecciosas, e malária desde 1901 (Öffentliche Vorlesungen...; Kraus, 1920b; Teichmann, 1954; 1968).

Sua inserção no círculo de imunologistas originou publicações e a fundação da Sociedade Alemã para Microbiologia, em 1908. No âmbito editorial, Kraus organizou com Levaditi o Handbuch der Technik und Methodik der Immunitätsforschung (1908), e foi editor, junto com Ernst Friedberger, Hans Sachs e Paul Uhlenhuth, da Zeitschrift für Immunitätsforschung und experimentelle Therapie (1909-1932) (Teichmann, 1968; Mazumdar, 1995, p.263-267).

As teorias imunológicas da virada do século XIX para o XX partiam sobretudo da prática para pensar suas bases teóricas, já que as inovações terapêuticas eram mais consensuais do que as teorias da imunidade. Segundo Tauber e Chernyak (1991, p.151-153), a primeira teoria da imunidade foi elaborada no início dos anos 1880 por Elie Metchnikoff, que introduziu o conceito de resposta ativa do organismo a uma infecção, em contraposição à concepção corrente que considerava o microrganismo um agente autônomo no processo de imunização. O desenvolvimento da soroterapia a partir dos anos 1890 incorporou aquele conceito base de Metchnikoff, mas não resultou em consenso quanto à natureza da resposta imunológica.

Ainda que não houvesse consenso, fato é que, além das vacinas profiláticas de Pasteur, começaram a surgir eficazes meios de cura, como os soros e as vacinas curativas. Desse modo, muitos acreditavam que a cura da maioria das doenças era apenas uma questão de tempo, 
tendo em vista a diversificação dos procedimentos terapêuticos. O relato de um médico inglês ilustra bem o novo ânimo despertado entre os cientistas do campo biomédico pelas promissoras curas através de produtos biológicos: "A medicina do futuro é a medicina das vacinas e dos soros'. O empirismo do passado cederá lugar aos métodos baseados em conhecimentos científicos, e o público não irá mais olhar a medicina com olhos céticos e medicar-se com panaceias ineficazes" (Allen, 1907, citado em Worboys, 1992, p.96; destaque do autor). ${ }^{3}$

Voltado para a pesquisa sorológica, Rudolf Kraus provavelmente compartilhava essa sensação de poder elaborar terapêuticos a partir das técnicas recém-desenvolvidas da soroterapia e da profilaxia vacínica. Entre 1895 e 1913, a maioria de seus trabalhos dividiu-se em três grandes áreas: reações sorológicas, imunização e teorias da imunidade.

De forma análoga ao que aconteceu com Robert Koch, os caminhos que levaram Kraus à América do Sul foram traçados também em função de sua situação profissional em Viena. Entre o ingresso no instituto vienense e a partida para Buenos Aires, Kraus acumulou cursos e períodos de trabalho em importantes instituições, e cargos na academia e administração imperial. No início de 1913, destacou-se pela liderança da expedição de combate ao cólera, disenteria e tifo abdominal que assolava o Exercito búlgaro durante a Guerra dos Bálcãs (1912-1913) (Rudolf Kraus, s.d.). As perspectivas de crescimento profissional eram, contudo, limitadas porque a diretoria dos institutos em que trabalhava (o Soroterápico e o de Patologia Experimental da universidade) estavam sob o comando de Richard Paltauf, que também detinha a cátedra de patologia experimental da Universidade de Viena. Além disso, e muito significativo, sua origem judaica provavelmente o impediu de almejar uma cátedra na Universidade de Viena. ${ }^{4}$

Assim, em 1913, Rudolf Kraus transferiu-se de Viena para Buenos Aires, aceitando convite para dirigir a mais importante instituição de pesquisa bacteriológica do país sul-americano. A Argentina vinha tendo forte crescimento econômico e populacional desde a década de 1870, com tão intenso fluxo de imigrantes, principalmente, italianos e espanhóis, que a população saltou de cerca de um milhão, em 1869, para quase oito milhões, em 1914. Além disso, a nova configuração política, instituída a partir de 1880, fortaleceu o poder do governo central, enfraquecendo as províncias. A economia, baseada sobretudo na pecuária, teve crescimento de 5\% ao ano na maior parte do período, elevando-se a área de criação de menos de meio milhão de hectares a quase 24 milhões às vésperas da Primeira Guerra Mundial (Conde, 2008, p.505; Gallo, 2008, p.512, 513). Em vista desse rápido crescimento, não é de surpreender que um cargo numa instituição argentina fosse considerado muito promissor. Em nota veiculada no British Medical Journal, em 3 de maio de 1913, lê-se a respeito de Kraus que: "sua posição social e financeira na Argentina será muito satisfatória, e suas oportunidades para o trabalho científico serão as melhores" (Special Correspondence, 1913, p.969). ${ }^{5}$

$\mathrm{Na}$ Argentina, Kraus gozaria, portanto, de status profissional prestigiado como diretor de um instituto cujos idealizadores pretendiam que viesse a ser a instituição de pesquisa e produção de imunobiológicos mais proeminente do país. Kraus teria a oportunidade de estabelecer grande parte das prioridades de pesquisa. Embora fosse imperioso tratar das doenças mais importantes para a região, alguns temas que abordara em Viena continuariam a ser pesquisados em Buenos Aires. 


\section{O desenvolvimento de produtos biológicos de uso terapêutico}

As primeiras décadas do século XX caracterizaram-se por intensa experimentação de novas terapias com base em materiais biológicos como soros e vacinas. Segundo Löwy (2005, p.675-677), a partir da descoberta da anafilaxia ${ }^{6}$ por Charles Richet e Paul Portier, em 1903, princípios terapêuticos da bacteriologia e de teorias fisiológicas populares no século XIX passaram a conviver no tratamento das doenças crônicas e infecciosas. Assim, nos anos 1920, coexistiam terapias com princípios diversos e, às vezes, opostos como a soroterapia e a proteinoterapia. ${ }^{7}$ Havia também a vacinoterapia, a vacinação tradicional (profilática) e a opoterapia (uso de extratos de órgãos para cura de doenças). A disponibilidade dessas diferentes técnicas de produção de substâncias e procedimentos terapêuticos representava incentivo a cientistas que tinham a oportunidade de trabalhar num instituto de pesquisa e produção nas regiões tropicais ou de dirigi-lo, como era o caso de Rudolf Kraus e Antonio Carini.

Nos primeiros anos como diretor do Instituto Bacteriológico do Departamento Nacional de Higiene de Buenos Aires, Rudolf Kraus organizou uma estrutura calcada, em parte, no exemplo do Instituto Oswaldo Cruz (IOC) à exceção do ensino, vertente importante deste último (Benchimol, 1990, p.27). A fabricação de soros, vacinas e produtos opoterápicos pelo instituto argentino pôde suprir toda a demanda nacional em poucos anos, e, durante a Primeira Guerra Mundial, a Argentina não dependia mais da importação desses produtos (Kraus, 1920a, p.3). As pesquisas em medicina tropical logo começaram a concorrer com as do Instituto Oswaldo Cruz, pois Kraus e seus colaboradores argentinos passaram a abordar diversos temas caros aos cientistas de Manguinhos, como a doença de Chagas e a leishmaniose (Neiva, 19 maio 1916). Deter-me-ei, contudo, apenas na fabricação de terapêuticos.

Entre 1914 e 1916, o Instituto Bacteriológico do Departamento Nacional de Higiene de Buenos Aires passou a produzir as vacinas antitífica, antiestafilocóccica, antiestreptocóccica, antipestosa, antiozenosa, antigonocóccica, antirrábica, tuberculina, vacina Coli, Virus Danysz; e os soros normal, antitetânico, antipestoso, antidiftérico, antidisentérico, antimeningocóccico, antiestreptocóccico e antiofídico (Kraus 1916, p.63; 1921, p.4). Comparando dados do instituto argentino com os do IOC no mesmo período (Benchimol, 1990, p.87; Kraus, 1921), observamos que a produção dos soros antidiftérico, antitetânico e antidisentérico era maior no primeiro, assim como a das vacinas antipestosa, antitética e antiestafilocóccica. A produção brasileira superava a argentina apenas em relação ao soro antiestreptocóccico. Cumpre salientar que também diferia o produto: enquanto o IOC produzia a vacina contra a peste da manqueira, o instituto argentino fabricava soro antiofídico, e soro e vacina contra a meningite.

No mercado médico brasileiro, a efervescência de produtos era notória. No índice de O Brasil Médico, entre 1914 e 1919, por exemplo, podemos encontrar diversos trabalhos sobre o uso de soros, vacinas (terapêuticas e profiláticas), secreções e hormônios na cura de doenças ou na atenuação de seus sintomas. Conforme mostrado por Benchimol e Teixeira (1993, p.177-180), a partir da década de 1920, o mercado privado de laboratórios e publicações atraiu muitos cientistas que trabalhavam na esfera pública. Sua transferência para a área privada ou o concomitante exercício das funções decorreu das crises enfrentadas pelos dois mais importantes institutos de produção de imunobiológicos no Brasil, o Oswaldo Cruz e o Butantan, e da própria expansão do uso desses produtos pelos médicos. Os autores informam 
que esses cientistas não se ocupavam apenas da produção privada desses terapêuticos, mas também de sua divulgação. A revista Medicamenta, por exemplo, era publicada por cientistas do IOC, além de Theofilo de Almeida do Departamento Nacional de Saúde Pública, enquanto a Sciencia Medica foi fundada por Arthur Neiva, em 1923, quando já se encontrava afastado do IOC, e por dois assistentes desse instituto, Olympio da Fonseca e César Pinto (Benchimol, Teixeira, 1993, p.178).

Outro evento que contribuiu para a efervescência do mercado de imunobiológicos no país foi a Primeira Guerra Mundial que, segundo Ribeiro (1997, p.480), provocou o estímulo da indústria farmacêutica no Brasil em razão da interrupção das importações de medicamentos europeus. A situação era igual na Argentina, que aprovara a lei n.9.652 de 8 de junho de 1915 outorgando ao Instituto de Química do Departamento Nacional de Higiene a preparação de substâncias farmacêuticas em falta no mercado (Fondo..., 1916). A guerra também serviu para assentar o uso dos produtos de origem biológica como, por exemplo, o soro antitetânico e antigangrenoso (Eckart, 2003, p.318-319).

A análise de dois catálogos de venda de produtos biológicos, um de 1918, do Laboratório Paulista de Biologia (LPB), e outro do Istituto Sieroterapico Milanese (ISM), de 1931, mostra o quanto era variada a oferta de terapêuticos e produtos de diagnóstico. Mostra também que se autorgava aos produtos credibilidade para uso mediante depoimentos de personalidadeschave da saúde pública, como, por exemplo, Carlos Chagas, ou de resumos explicativos sobre as etapas de sua fabricação. Benchimol e Teixeira (1993, p.178) demonstram que o prestígio do IOC era usado como garantia de qualidade para produtos vendidos por laboratórios particulares comandados por funcionários daquele instituto.

O Manual de Bioterapia escrito pelo doutor Mario Delor, por exemplo, ainda que se pretendesse manual, tinha o caráter de catálogo de vendas e serviu como propaganda para o LPB. A publicação explicava os princípios da opoterapia, vacinoterapia, soroterapia específica e soroterapia não específica, e a forma de preparo de todos os trinta produtos entre soros, vacinas e hormônios. Além, é claro, de citar todos os trabalhos científicos envolvidos em sua fabricação, com o intuito de assegurar caráter de eficácia ao produto. Apresentado como meio de informação para os clínicos e não explicitamente como catálogo de produtos, o veículo revelava as conquistas da bioterapia como próprias do LPB. Ao final de cada seção constava sempre a recomendação: "Receitem sempre a vacina contra a coqueluche do Laboratório Paulista de Biologia" (Delor, 1918, p.154).

A publicação do ISM, por sua vez, é formatada de modo mais comercial, com a indicação de preços, dose a ser aplicada e forma de armazenamento dos mais de cinquenta produtos à venda. Sua validação é justificada nessa publicação, assim como na de Delor, pela reprodução dos resultados obtidos por cientistas. Sendo tradução do original italiano para o português, o catálogo do ISM incorporou relatos de médicos brasileiros, mais convincentes para o públicoalvo. Assim, na seção Opotherapia Mammaria, encontramos em nota a indicação de que um médico do Rio Grande do Sul, o doutor Emilio Candia, teria publicado resultados favoráveis sobre o produto Ghiandola Mammaria, e que o doutor Antonio Vecchio enviava para o instituto na Itália seus resultados, também favoráveis. Nas últimas páginas da publicação reproduziu-se carta de Carlos Chagas, datada 8 de outubro de 1917, atestando a qualidade dos soros antidiftérico e antitetânico e de outros produtos do ISM ao diretor-geral da Saúde 
Pública (Sôros..., 1931, p.512). O prestígio do cientista e da instituição asseguravam a qualidade dos produtos.

Na época, Chagas era diretor do Instituto Oswaldo Cruz, que ainda não tinha a prerrogativa de avaliar os produtos biológicos importados, só adquirida em 1920, com o decreto de 15 de setembro (Benchimol, 1990, p.58). O controle sobre a comercialização era, assim, pouco rígido como se observa pelo fato de o instituto carioca ainda não ser oficialmente responsável por essa avaliação, bem como pelo intervalo entre o ano da carta de recomendação de Chagas e o da publicação da terceira edição do catálogo (1931). Na legislação corrente não estava prevista a fiscalização frequente dos produtos, apenas avaliação inicial que resultava em licença concedida pelo órgão competente (Brasil, 18 mar. 1914; Brasil, 2 jan. 1920). Com isso, é de supor que, uma vez aprovado, um terapêutico só passaria por nova avaliação caso ocorresse algum incidente com seu uso. Dessa forma, uma empresa estrangeira que tivesse licença datada de 1900 para venda de um soro terapêutico poderia comercializá-lo até a década de 1920 sem outra avaliação.

O precário controle estatal combinava-se à falta de opção para o tratamento de variadas doenças infecciosas para contribuir com o crescimento desse mercado. Nos primeiros anos do século XX, vários agentes patogênicos ainda não eram completamente compreendidos em relação a sua atuação no organismo humano. Com isso, a experimentação de novos terapêuticos para doenças que ainda não tinham cura era ilimitada. Uma vez compreendido o processo de infecção de um microrganismo, a estratégia de formulação de um terapêutico se restringiria. As doenças causadas por toxinas bacterianas, por exemplo, como a difteria e o tétano, passaram a ser tratadas de maneira mais eficaz quando se identificaram as toxinas como os agentes das reações patológicas no organismo.

Outro facilitador da elaboração de produtos era a atuação limitada desse controle estatal, que só avaliava a inocuidade e a eficácia dos produtos, deixando os possíveis efeitos colaterais a cargo dos médicos. A falta de legislação que regulasse os limites da experimentação em humanos facilitava, assim, a invenção. Desse modo, qualquer médico que atuasse nos serviços públicos ou que tivesse a sua disposição uma razoável quantidade de doentes poderia, a partir dos materiais deles coletados, tentar desenvolver um meio de cura e testá-lo nesses doentes, sem muitos empecilhos. Ademais, em tempos de epidemia, caso a doença não contasse com algum método de cura, a experimentação também seria rapidamente consentida. $\mathrm{O}$ aparecimento de uma epidemia era boa ocasião para testar novos produtos. Em artigo sobre a vacinoterapia da coqueluche na Novotherapia, essa constelação de fatos é explicitada: "Tivemos assim oportunidade de usar, em larga escala, a vacina contra a coqueluche, 'servindo-nos de diversas qualidades de vacinas' e experimentando-as em doentes de diferentes idades" (Clerici, 1924, p.35; grifo meu).

Como o processo de validação de terapêuticos ainda não estava regulado por leis, o tempo entre a divulgação de um novo produto e sua avaliação pelos especialistas era muito variável, o que dava muitas vezes ao inventor um período de prestígio. Com isso, o domínio sobre uma inovação terapêutica conferia momentaneamente a seu inventor autoridade e renome científico. Isso havia ocorrido na década de 1880 com os tratamentos para a febre amarela, desenvolvidos por Domingos Freire sob a forma de vacina profilática e por Giuseppe Sanarelli sob a forma de soro, ambos posteriormente desacreditados (Benchimol, 1999). 
A experimentação humana não controlada também ocorria por desconfiança dos médicos em relação a novos métodos. Ainda que a reputação do médico 'inventor' fosse incontestável, o receio quanto ao novo terapêutico só era afastado depois do teste. Conforme Pagani-Cesa (1925, p.22), "todo produto para merecer as simpatias de um médico, deve antes ter sido favorável em um caso ao menos de sua observação, o que constitui maior valor que dez publicações a respeito". Assim, no período em análise, a forma mais corriqueira de divulgar e provar a eficácia de um novo tratamento era a experimentação humana. Kraus, por exemplo, declara quanto à inadequação de comparar testes em animais e em humanos: "na minha opinião, a experimentação animal não é capaz de resolver muitos dos problemas da patologia humana, e, se desejamos ver adiante nesse vasto terreno, devemos levar a cabo experiências terapêuticas no homem" (Kraus, 1916, p.68). ${ }^{8}$

Na Europa, o controle sobre a experimentação humana variava de país a país. O episódio de Lübeck, na Alemanha, no início da década de 1930, deu ensejo ao estabelecimento de uma das primeiras formas de regulação da pesquisa médica em humanos no Ocidente, o Richtlinien (diretrizes). Na França, a situação se manteve, pois o incidente de Lübeck foi considerado produto da manipulação equivocada da vacina pelos alemães (Bonah, Menut, 2004, p.112-113, 123). A experimentação em seres humanos começou a ser mais debatida internacionalmente após os julgamentos de Nuremberg que expuseram ao mundo as terríveis experiências perpetradas nos campos de concentração nazistas (Kottow, 2008, p.3).

Os produtos ou procedimentos terapêuticos elaborados por Kraus na Argentina foram testados nos hospitais ligados ao Departamento Nacional de Higiene e muitos deles contaram com a colaboração de pesquisadores argentinos. Em 1916, Kraus fundou a Sociedade Sul-americana de Microbiologia, Patologia e Higiene, cujo primeiro congresso ocorreu em Buenos Aires, de 17 a 24 de setembro daquele ano, sendo apresentados os trabalhos: "Estudios sobre heterobacterioterapia y terapia protéica"; "Sobre el tratamento del carbúnculo humano com el suero normal"; "Relación sobre la lepra"; e "Sobre el tratamento de la coqueluche com Antitosina" (Kraus, Carbonel, 1917). Reunindo cientistas da maioria dos países da América do Sul, o congresso serviu para a divulgação dos trabalhos do Instituto Bacteriológico do Departamento Nacional de Higiene de Buenos Aires, dirigido por Rudolf Kraus desde 1913, e para sua própria projeção no meio científico da região.

Procedimentos terapêuticos preconizados por ele foram a "terapia proteica" e a "heterobacterioterapia" (Penna, Bonorino Cuenca, Kraus, 1919). A primeira baseava-se na administração intravenosa de soluções derivadas de bactérias que conteriam "corpos albuminoides" (proteínas), e a segunda consistia na injeção intravenosa de uma espécie de bactéria diferente daquela que estava causando a doença. A terapia proteica derivou da heterobacterioterapia porque, utilizando-se apenas os filtrados das culturas, notou-se que o efeito curativo não provinha das bactérias e sim dos tais "corpos albuminoides" (Kraus, Penna, Bonorino Cuenca, 1917, p.827-828). Supunha que a oscilação térmica produzida com a injeção de substâncias albuminoides estimulava as defesas do organismo contra a infecção (Ibars, 1924, p.3). O princípio embasava também o uso do soro normal de bovinos na cura do carbúnculo humano, o quarto trabalho relativo a terapias apresentado no Congresso de Buenos Aires (Kraus, Penna, Bonorino Cuenca, 1917). 
A injeção de substâncias derivadas de outros organismos visando à obtenção da cura de doenças não era prática recente. O próprio Wright já havia observado, em 1918, que a injeção de pneumococos diminuía a mortalidade por pneumonia e outras doenças (Ibars, 1924, p.5). Entretanto, afirmavam Kraus, Penna e Bonorino Cuenca (1917, p.823) que a heterobacterioterapia havia sido fundada por Kraus e Salvador Mazza.

A prioridade na concepção desse procedimento terapêutico é controversa. Como mencionei, várias terapias com princípios divergentes conviviam na prática médica no início do século $\mathrm{XX}$. A autoria do desenvolvimento de novos procedimentos era difícil num período em que proliferava a experimentação com variadas substâncias. Num artigo publicado em 1924 na Revista Veterinaria de España, Juan Ibars (1924, p.4) atribui a Rudolf Schmidt a introdução da proteinoterapia, que se teria disseminado, primeiramente, na Alemanha, Áustria e nos EUA. Encontramos no British Medical Journal trabalhos sobre a proteinoterapia (protein-therapy) a partir de 1918 de autoria de A. Auld. Na Wiener klinische Wochenschrift, publicação da Sociedade dos Médicos de Viena, também se encontram trabalhos sobre proteinoterapia em 1916 e 1917. Segundo Weichardt (1918, p.582), a aplicação de proteínas na cura de doenças infecciosas já havia sido sugerida, em 1910-1912, por ele mesmo e por Schittenhelm na Zeitschrift für experimentelle Pathologie und Therapie. Afirmou ainda que Kraus não teria introduzido o princípio da heterobacterioterapia, pois fora sugerido por Th. Rumpf em 1893.

Assim, com tantos novos tratamentos e substâncias em elaboração e experimentação, era menor a chance de um novo terapêutico prevalecer como tratamento hegemômnico, superando os demais. Foi o caso da vacina profilática da lepra, de Kraus, que, apesar de ter sido apresentada na Conferência Americana da Lepra, em 1922, no Rio de Janeiro, não recebeu menção nas resoluções do evento, que mantiveram a indicação do óleo de chalmogra como terapêutico (Conferência...., 1922, p.276). O médico Heraclídes César de Souza-Araújo (1932, p.238), um dos maiores especialistas em lepra no Brasil, recebeu a vacina feita por Kraus durante o congresso de 1916, mas não se pronunciou a respeito de sua eficácia em nenhum trabalho de sua autoria.

O único terapêutico que obteve grande repercussão na Argentina, no Brasil e no Uruguai foi a 'antitoxina Kraus' ou 'vacina Kraus' para coqueluche, que passou a ser reproduzida por outros médicos. As demais criações terapêuticas do bacteriologista vienense nunca alcançaram o prestígio que essa vacina teve nos anos 1910 e 1920.

\section{A 'antitosina Kraus' ou'vaccina Kraus'}

Os produtos elaborados por Kraus não foram monopolizados por ele nem por qualquer firma ou representante comercial. As técnicas de produção foram reveladas em periódicos, apesar de muitas vezes não serem descritas em detalhes. O método de fabricação da vacina terapêutica contra a coqueluche, por exemplo, foi extensamente apropriado e modificado. A 'antitosina Kraus' foi, reitero, o único produto biológico desenvolvido por Rudolf Kraus que obteve repercussão entre os clínicos de Buenos Aires, São Paulo, Rio de Janeiro e Montevidéu.

Em 1916, ele apresentou no congresso da Sociedade Sul-americana de Microbiologia, Patologia e Higiene o trabalho sobre o novo método para o tratamento da coqueluche, calcado no uso do escarro de crianças enfermas. ${ }^{9} \mathrm{O}$ material era recolhido na primeira semana da 
doença, esterilizado com éter e examinado em busca do bacilo de Koch (tuberculose). Embora a dose e a forma de administração (intervalo entre cada aplicação e momento em que a vacina devia ser administrada) ainda fossem incertos para Kraus, ele afirmava que era consensual a redução dos sintomas mais graves (convulsões, vômito e tosse) com o uso da 'antitosina'. Para verificar a eficácia do novo terapêutico, foram feitos testes em instituições buenairenses: Hospital del Niños, pelo doutor Juan Parrera; Hospital Muñiz, pelos doutor José Penna e Bonorino Cuenca; e Casa dos Expósitos, pelos doutores Naveiro e Siquot (Kraus, 1917).

Segundo Kraus, a prática do uso de material coletado de pacientes para produzir vacinas teve origem com Jenner e continuava adotada por vários médicos e cientistas. Com exceção das vacinas contra a raiva e a varíola, eram poucos os exemplos bem-sucedidos. O cientista austríaco referia-se, no entanto, às vacinas terapêuticas com base na técnica desenvolvida pelo médico inglês Almroth Wright no início do século XX. Ao final do artigo reproduzia-se comentário de José Lignières que, em discussão com Antonio Carini, Telemaco Susini e Kraus sobre a esterilidade da 'antitosina', relatou que também fazia testes com produtos biológicos.

Na Argentina, a 'vacina Kraus' foi utilizada por outros médicos, que se pronunciaram favoravelmente, fornecendo seus relatos como respaldo ao invento de Kraus (Penna, Bonorino Cuenca, 1915). Conforme Ricardo P. Levalle: "sem medo de exageros, podemos afirmar que esse novo tratamento da coqueluche é infinitamente superior aos anteriormente usados" (Kraus, 1917, p.494). ${ }^{10}$ A vacina teria sido usada em mais de quinhentos pacientes e até aquele momento não ocorrera nenhum incidente. Era continuamente utilizada nos hospitais Muñíz e de los Niños, em Buenos Aires. A leitura desse artigo de Kraus fornece, assim, indícios de que a experimentação de novos terapêuticos em humanos era difundida.

No Brasil, o novo terapêutico disseminou-se depois do congresso de 1916, sabendo-se que, no próprio evento, Ulysses Paranhos, do LPB, apresentou trabalho em que relatava resultados favoráveis com a 'vacina Kraus' em São Paulo. Ela já vinha sendo produzida no estado pelo pelo LPB e pelo Instituto Bacteriológico, então dirigido por Theodoro Bayma. A partir de 1917, os resultados do seu uso no país eram divulgados em revistas brasileiras como União Farmacêutica, Arquivos Brasileiros de Medicina e Anais Paulistas de Medicina e Cirurgia. ${ }^{11}$ Naquele mesmo ano, o médico Carvalho Lima (1917, p.10), que viria a ser diretor do Instituto Bacteriológico em 1922-1923, defendeu tese de doutorado na Faculdade de Medicina do Rio de Janeiro intitulada Contribuição ao estudo da vacinoterapia da coqueluche, na qual apresentava os resultados obtidos com a 'vacina Kraus' e propunha modificações ao método de fabricação. Em 1919, Theophilo de Almeida Junior, médico da Santa Casa de Turvo, em Minas Gerais, comparou diversos tratamentos para a coqueluche e julgou a vacina de Kraus superior (Fighera, 1923, p.23-27). Ela se tornou tão conhecida, que chegou a ser solicitada ao Instituto Oswaldo Cruz, em carta de 27 de maio de 1920. Os representantes da firma Domiciano Maia \& Filho solicitaram o terapêutico que, no entanto, não era produzido pelo IOC (Fundo..., 1920-1921).

A vacinoterapia da coqueluche já era corrente na década de 1920 entre os pediatras, sendo recomendada em diversos manuais como, por exemplo, o de Angelo de Azevedo Santos Moreira, Formulario de terapêutica infantil, e de Leoncio de Queiroz, Molestias dos lactentes e seu tratamento (Stanick, 2010). Nas páginas da revista Novoterapia, nos anos 1920, são recorrentes os artigos que versam sobre a vacinoterapia em diversas doenças. A vacina ou método de Kraus não foi citada porque a revista era publicada pela Novotherapica Italo-brasileira, que 
vendia uma vacina curativa contra a doença feita no Istituto Sieroterapico Milanez da Itália. Outras vacinas contra a doença eram vendidas pelo Laboratório Silva Araujo, pelo Instituto Bacteriológico, sob a direção de Carvalho Lima, e pelo LPB, no qual sua produção alcançava cerca de mil ampolas por mês. As vacinas das duas últimas instituições adotavam o método de produção preconizado por Kraus, salvo algumas modificações feitas por Carvalho Lima (Fighera, 1923, p.23-24, 28).

A tese de doutorado de Caetano Raphael Fighera, submetida à Faculdade de Medicina e Cirurgia de São Paulo, em 1923, traz um dos relatos mais completos sobre o uso da 'antitoxina Kraus' no Brasil. Outras duas teses de doutorado sobre a coqueluche foram publicadas no período: a de José Felix Paschoal Júnior, apresentada em 1921, à Faculdade de Medicina do Rio de Janeiro, e a de Francisco Osmond Coelho, defendida em 1927 na mesma instituição. Ambas reiteravam a eficácia do produto desenvolvido por Rudolf Kraus (Paschoal Júnior, 1921; Coelho, 1927).

Surgiu nessa época outro terapêutico para o tratamento da coqueluche: o 'Pertussol', desenvolvido por Aleixo de Vasconcelos, titular da cadeira de microbiologia da Faculdade de Medicina do Rio de Janeiro. Consistia na combinação da 'antitoxina Kraus' com os agentes patogênicos da doença. A referência consta em trabalho de Stanick (2010, p.18), em que são reproduzidas várias citações favoráveis à vacinoterapia, oriundas de estudos de médicos brasileiros como, por exemplo, Leonel Gonzaga e Renato Kehl. O primeiro defenderia essa terapêutica até os anos 1950, quando os antibióticos já eram considerados os medicamentos mais eficazes no combate às infecções bacterianas.

\section{Comércio lucrativo na América do Sul}

Embora não tenha lucrado com nenhum de seus produtos bioterápicos, em seu livro 10 Jahre in Südamerika Rudolf Kraus (1927, p.158) declara que a perspectiva de lucros com a venda de vacinas e soros na América do Sul era muito promissora. Em sua opinião, o comércio de imunizantes para animais de criação movimentava milhões na Argentina, que recebia produtos dos EUA e da Europa. Em resenha do livro, publicada na Wiener medizinische Wochenschrift, ele foi caracterizado como guia informativo para possíveis investimentos no mercado de produtos biológicos nos países do Cone Sul:

Seu objetivo [do livro] é propagar os conhecimentos sobre esses países, especialmente sob os aspectos higiênicos e médicos, e também possibilitar um panorama da situação atual da saúde e assistência públicas, bem como a medicina veterinária desses países. Com isso, ele pode fomentar interesses sociais e econômicos. Para nós é importante que as políticas populacionais desses países estimulem medidas de higiene e também facilitem a imigração (Glaser, 1928, p.133). ${ }^{12}$

O livro é resultado da experiência de Kraus na Argentina e no Brasil e da edição de palestras ministradas por ele em Viena e Praga após seu retorno à Europa na década de 1920.13 O capítulo que discorre sobre as doenças veterinárias, por exemplo, apoia-se em sua palestra de janeiro de 1924 na Sociedade de Veterinários em Viena. Argentina, Uruguai e Brasil foram retratados como países que possuíam infraestrutura científica básica para a pecuária, isto é, 
escolas de veterinária, profissionais qualificados, laboratórios produtores de soros e vacinas veterinários, e pouco controle do Estado sobre tal produção. Nesse ponto, Kraus enfatizava a possibilidade de produtos europeus entrarem no mercado platino. A falta de regulação rígida sobre os produtos biológicos de uso humano e veterinário é constantemente mencionada no livro do cientista austríaco.

As províncias do norte da Argentina, o Uruguai e o sul do Brasil eram regiões de criação de gado e outros animais. No início do século XX, houve aumento expressivo da atividade pecuarista e diversificação das atividades a ela relacionadas no Uruguai (Moraes, 2003, p.269270) e na Argentina (Conde, 2008, p.493, 499), o que levou também ao crescimento dos laboratórios produtores de soros e vacinas de uso veterinário.

\section{Considerações finais}

O objetivo deste artigo foi analisar, com base na trajetória profissional de Rudolf Kraus, algumas das circunstâncias que deixavam as regiões tropicais mais atraentes à pesquisa biomédica em comparação com as regiões temperadas. Mesmo a Argentina, considerada então país de clima temperado, oferecia as mesmas condições favoráveis: fraco controle estatal sobre a produção de imunobiológicos, alta demanda de produtos veterinários e humanos; poucos grupos de pesquisa estabelecidos.

Priorizamos aqui seus trabalhos que resultaram em produtos terapêuticos ou procedimentos terapêuticos que gozaram de aceitação médica. Vimos que a disseminação de um novo terapêutico se dava de maneira bastante pessoal, através dos contatos que o cientista possuísse, como foi o caso da 'vacina Kraus' para a coqueluche.

Na virada do século XIX para o XX, as regiões tropicais exerciam grande atração sobre cientistas europeus que as consideravam 'oásis' de novas doenças a identificar ou locais propícios à busca de novos terapêuticos. Nesse sentido, a chance de dirigir um instituto de pesquisa e produção biomédica era grande privilégio para um imunologista que dominava técnicas de produção de soros e vacinas. Além disso, o instituto localizava-se em região cuja variedade de doenças era supostamente maior, e cuja produção científica ainda não podia ser comparada à europeia, principalmente em termos numéricos.

Há que pesar também a situação profissional do cientista no momento em que decidiu abandonar uma instituição de pesquisa europeia para se aventurar em terras longínquas. As limitações na carreira ou a própria concorrência entre os pares poderiam dar motivos para a transferência de instituições, bem como a crença de que a concorrência nos países de destino seria mais branda.

O comércio de produtos bioterápicos mostrava-se promissor em países como Brasil, Argentina e Uruguai, que, possuindo centros urbanos em expansão e, principalmente, rebanhos em expansão de animais de criação, começavam a ser vistos como mercados promissores para a venda de vacinas e soros de uso humano e animal tanto às instituições nativas quanto aos laboratórios estrangeiros, como o Instituto Sieroterápico Milanz, a Parke \& Davis, a Bayer e outros, que possuíam revendedores no Brasil.

Os terapêuticos que Rudolf Kraus elaborou durante sua estada em Buenos Aires eram testados nos hospitais subordinados à administração pública de saúde, ou seja, com a anuência 
do chefe da saúde pública. A fabricação de produtos biológicos no Brasil e na Argentina ainda requer análises mais amplas. No entanto, já se pode afirmar que a elaboração e difusão de um terapêutico demandava a participação de diversos atores até que a novidade se consolidasse junto aos médicos e outros usuários. Além dos colaboradores científicos, que ajudavam no desenvolvimento do novo terapêutico, participavam os clínicos testando-o em seus pacientes e concedendo ou não seu aval ao novo produto. Não havia na época legislação que regulasse a experimentação em humanos, por isso, era disseminada aquela prática com terapêuticos de origem biológica.

\section{NOTAS}

1 "Bei uns zu Hause ist nun schon so gründlich aufgearbeitet und die Concurrenz eine so gewaltige, da es sich wirklich nicht mehr lohnt dort zu forschen. Hier drau en aber, da liegt noch das Gold der Wissenschaft auf der Stra e. Wie viel Neues habe ich gesehen und gelernt, als ich zum ersten Mal nach Afrika kam". Nessa e nas demais citações de textos publicados em outros idiomas, a tradução é livre.

${ }^{2}$ Segundo Gradmann (2005, p.255), ao se estudar a biografia de um cientista, devem ser feitas duas perguntas: como surge e se desenvolve a paixão pelas viagens, ou seja, como as circunstâncias da vida do biografado influenciam essa escolha e como o seu trabalho é por ela orientado, como, por exemplo, a priorização de determinados objetos de pesquisa? As viagens eram particularidades da trajetória de Koch ou eram significativas para a história da bacteriologia?

3 “'The medicine of the future is the medicine of vaccines and sera'. The empiricism of the past will give away to the methods based upon scientific knowledge and the public will no longer look upon medicine with a sceptical eye and dose themselves with ineffective nostrusm".

${ }^{4} \mathrm{O}$ antissemitismo em Viena, na virada do século XIX para o XX, teve seu ápice após a eleição de Karl Lueger para a presidência do Parlamento austríaco, em 1895, e a partir de 1907, quando os socialistas cristãos se aliaram aos conservadores e passaram a ser maioria no Parlamento (Lichtblau, 2009, p.41). O antissemitismo estava presente nas universidades alemãs desde o século XIX (Hammerstein, 1995, p.69-75). É muito provável que sua herança judaica o tenha impedido ou dificultado qualquer ascensão na Universidade de Viena. A posição em uma cátedra seria buscada futuramente na Argentina, em 1920, porém, sem êxito (Kraus, 1920b).

5 "His financial and social position in the Argentine will be very satisfactory, and his opportunities for scientific work will be of the most extensive kind".

${ }^{6} \mathrm{O}$ fenômeno da anafilaxia ocorria quando, após a sensibilização por certa substância (proteínas, bactérias etc.), o organismo reagia fortemente a sua injeção. Embora o fenômeno estivesse calcado na especificidade da substância sensibilizadora, deu ensejo a pesquisas sobre as curas não específicas. Como não se conseguia identificar um anticorpo específico na maioria das reações anafiláticas, seu estudo não foi abraçado pelos imunologistas e sorologistas, e sim por patologistas e fisiologistas (Löwy, 2005, p.679).

${ }^{7}$ A soroterapia baseava-se na especificidade entre antígeno e anticorpo ou toxina e antitoxina. Assim, quando se injetava soro contra a difteria em um doente, as antitoxinas neutralizavam as toxinas diftéricas. A proteinoterapia calcava-se no desequilíbrio repentino do organismo como forma de criar ambiente desfavorável para os germes causadores da infecção, neutralizando-se o processo infeccioso. Ademais, a injeção de proteínas estimulava as defesas do organismo, que, 'percebendo' a infecção, passavam a atuar de maneira mais eficaz (Ibars, 1924).

8 “Según mi critério, la experimentación animal no es capaz de resolver muchos problemas de la patologia humana, y se deseamos ver adelante em este vasto terreno, debemos llevar a cabo experiências terapeuticas em el hombre".

${ }^{9}$ A primeira comunicação sobre seu novo terapêutico foi feita, no entanto, na Asociación Médica Argentina em 8 de novembro de 1915 (Kraus, 1915).

10 "Sin temor de pecar de exagerados, pudemos afirmar que este nuevo tratamento de la coqueluche es infinitamente superior a los anteriormente usados".

${ }^{11}$ Notícias veiculadas na seção Bibliografia (1917) da Revista del Instituto Bacteriológico del Departamento Nacional de Higiene. 
12 "Sein Zweck ist, die Kenntnisse über dieser Länder besonders in hygienieschen und medizinischen Hinsicht zu verbreiten, einen Einblick in den derzeitigen Stand der Öffentliche Gesundheits- und Wohlfahrtspflege sowie der Veterinärmedizin dieser Staaten zu ermöglichen und damit auch geistige und wirtschaftliche Interessen zu fördern. Von uns ist von Wichtigkeit, da diese Staaten Bevolkerungspolitik treiben, dieselben durch hygienische Ma nahmen fördern, aber auch die Einwanderung begünstigen".

${ }^{13}$ O capítulo 13, "Trypanosomenerkrankungen. Die Chagas krankheit, Thyreoiditis parasitaria, Kropf und Kretinismus in Südamerika" (Tripanossomiases. Doença de Chagas, tireoidite parasitaria, bócio e cretinismo na América do Sul), foi resultado de uma palestra dada na Gesellschaft für innere Medizin (Sociedade de Medicina Interna) de Viena em 19 de novembro de 1925. O capítulo 19, "Schädigungen und Vergiftungen durch giftige Tiere (Schlangen, Spinnen, Skorpione). Über Giftschlangen in Südamerika. Serumbehandlung der Schlangebisse" (Ferimentos e envenenamentos por animais peçonhentos - cobras, aranhas, escorpiões. Sobre as cobras venenosas na América do Sul. Tratamento com soro da picada de cobra.), resultou da palestra ministrada na Wiener Biologischen Gesellschaft (Sociedade Vienense de Biologia), sem data. E o capítulo 21, "Über Tierseuchen in Südamerika" (Sobre doenças veterinárias na América do Sul), havia sido apresentado na Gesellschaft der Tierärzte in Wien, em 19 de janeiro de 1924 (Kraus, 1927, p.91, 125, 156).

\section{REFERÊNCIAS}

BENCHIMOL, Jaime Larry.

Dos micróbios aos mosquitos: febre amarela e revolução pasteuriana no Brasil. Rio de Janeiro: Editora Fiocruz; EdUFRJ. 1999.

BENCHIMOL, Jaime Larry.

Manguinhos do sonho à vida: a ciência na Belle Époque. Rio de Janeiro: Casa de Oswaldo Cruz. 1990.

BENCHIMOL, Jaime Larry; TEIXEIRA, Luiz Antonio.

Cobras, lagartos e outros bichos: uma história comparada dos institutos Oswaldo Cruz e Butantan. Rio de Janeiro: EdUFRJ. 1993.

BERGER, Silvia.

Öffentliche Resonanzen. In: Berger, Silvia. Bakteriologie in Krieg und Frieden: Eine Geschichte der medizinischen Bakteriologie in Deutschland, 1890-1933. Göttingen: Wallstein. p.77-90. 2009.

BIBLIOGRAFIA.

Bibliografia. Revista del Instituto Bacteriológico del Departamento Nacional de Higiene, Buenos Aires. 1917.

BONAH, Christian; MENUT, Philippe.

BCG vaccination around 1930: dangerous experiment or established prevention? Debates in France and Germany. In: Volker, Roelcke; Maio, Giovanni. Twentieth Century ethics of human subjects research: historical perspectives on values, practices, and regulations. Stuttgart: Franz Steiner. p.111-127. 2004.

BRASIL.

Decreto n.3.987, de 2 de janeiro de 1920.

Reorganiza os serviços da Saúde Publica.

Disponível em: http://www6.senado.gov.br/ legislacao/ListaPublicacoes.action?id=48173\&tip oDocumento=DEC\&tipoTexto=PUB. Acesso em: 10 nov. 2012.2 jan. 1920.

\section{BRASIL.}

Decreto n.10.821, de 18 de março de 1914. Dá novo regulamento à Directoria Geral de Saúde Publica. Disponível em: http://www6.senado. gov.br/legislacao/ListaPublicacoes.action?id=5 5671\&tipoDocumento=DEC\&tipoTexto=PUB. Acesso em: 10 nov. 2012. 18 mar. 1914.

\section{CASSIER, Maurice.}

Appropriation and commercialization of the Pasteur anthrax vaccine. Studies in History, Philosophy of Biological and Biomedical Sciences, Leeds, v.36, p.722-742. 2005.

CLERICI, Alessandro.

A vaccinotherapia da coqueluche. Novotherapia, São Paulo, v.4, n.24, p.24-41. 1924.

COELHO, Francisco Osmond.

Da vaccinotherapia na coqueluche. Tese apresentada à Faculdade de Medicina do Rio de Janeiro, Rio de Janeiro. 1927.

CONDE, Roberto Cortés.

O crescimento da economia argentina, 1870-1914. In: Bethell, Leslie (Org.). História da América Latina, de 1870 a 1930. São Paulo: EdUSP, p.475-508. 2008.

\section{CONFERÊNCIA...}

Conferência Americana da Lepra: editoriaes.

Brasil Medico, Rio de Janeiro, v.36, p.276. 1922.

DELOR, Mario.

Manual de Biotherapia. São Paulo: Laboratório Paulista de Biologia. 1918.

ECKART, Wolfgang U.

"Der grösste Versuch, den die Einbildungskraft ersinnen kann": Der Krieg als hygienischbakteriologisches Laboratorium und Erfahrungsfeld. In: Eckart, W.U.; Gradmann, Christoph. Die Medizin und der Erste Weltkrieg. Herzbolzheim: Centaurus. p.299-319. 2003. 
FIGHERA, Caetano Raphael.

Vaccino-theapia, ethero-therapia e protein-therapia no tratamento da coqueluche. Tese apresentada à Faculdade de Medicina e Cirurgia de São Paulo, São Paulo. 1923.

FONDO...

Fondo Ministerio del Interior. Legajo 17. (Archivo Intermedio/Archivo General de La Nación, Buenos Aires). 1916.

FUNDO...

Fundo Instituto Oswaldo Cruz. Seção Direção. Série Cópia de Cartas. (Departamento de Arquivo e Documentação/Casa de Oswaldo Cruz/Fiocruz, Rio de Janeiro). 1920-1921.

GALLO, Ezequiel.

A Argentina: sociedade e política, 1880-1916. In: Bethell, Leslie (Org.). História da América Latina, de 1870 a 1930. São Paulo: EdUSP. p.509-542. 2008.

GLASER, Erhard.

Zehn Jahre Südamerika. Wiener medizinische Wochenschrift, Viena, v.78, n.4, p.133-134. 1928.

GRADMANN, Christoph.

Auf Reisen: Forschungsexpeditionen Robert Kochs als private und wissenschaftliche Praxis. In: Gradmann, Christoph. Krankheit im Labor: Robert Koch und die medizinische Bakteriologie. Göttingen: Wallstein. p.253-345. 2005.

HAMMERSTEIN, Notker.

Habilitation und Berufpraxis. In: Hammerstein, Notker. Antisemitismus und Deutsche Universitäten, 1871-1933. Frankfurt am Main; New York: Campus. p. 69-75. 1995.

IBARS, Juan.

La proteinotherapia en medicina veterinária.

Revista Veterinaria de España, Barcelona, v.16, n.1, p.3-8, jan. 1924.

KOTTOW, Miguel.

História da ética em pesquisa com seres humanos. RECIIS, Rio de Janeiro, v.2, supl.1, p.7-18. 2008.

KRAUS, Rudolf.

10 Jahre Südamerika: Vorträge über Epidemiologie und Infektionskrankheiten der Menschen und Tiere. Jena: Gustav Fischer. 1927.

KRAUS, Rudolf.

El Instituto Bacteriológico del Departamento

Nacional de Higiene: en su quinto aniversario.

Buenos Aires: Ministério del Interior. 1921.

KRAUS, Rudolf.

El Instituto Bacteriológico del Departamento

Nacional de Higiene y su labor. Buenos Aires:

Libreria Las Ciencias, 1920a.
KRAUS, Rudolf.

Antecedentes y trabajos: presentados para optar a la Cátedra de Microbiología de la Faculdade de Medicina. Buenos Aires: Imprenta Cosmos. 1920b.

KRAUS, Rudolf.

Sobre el tratamiento da coqueluche com antitoxina. In: Kraus, Rudolf; Carbonel, Manuel V. Primera Conferencia de la Sociedad Sud Americana de Higiene, Microbiología y Patología. Buenos Aires: Flaiban y Camillon. p.489-511. 1917.

KRAUS, Rudolf.

Organizacion y funcionamento del instituto. In: Kraus, Rodolfo (Ed.). Instituto Bacteriológico del Departamento Nacional de Higiene:

memoria informativa. Buenos Aires: Instituto Bacteriológico del Departamento Nacional de Higiene. p.37-71. 1916.

KRAUS, Rudolf.

Nuevo tratamento de la tos convulsa. Revista de La Asociación Médica Argentina, Buenos Aires, v.23, p.1381-1389. 1915.

KRAUS, Rudolf; CARBONEL, Manoel V. Primera Conferencia de la Sociedad Sud Americana de Higiene, Microbiología y Patología. Buenos Aires: Imprenta Flaiban y Camillon. p.151-165. 1917.

KRAUS, Rudolf; PENNA, Jose.; BONORINO CUENCA, Juan. Estudios sobre la heterobacterioterapia y terapia proteica. In: Kraus, Rudolf; Carbonel, Manuel V. Primera Conferencia de la Sociedad Sud Americana de Higiene, Microbiología y Patología. Buenos Aires: Imprenta Flaiban y Camillon, p.815-865. 1917.

LICHTBLAU, Albert.

Antisemmitismus 1900-1938: Phasen, Wahrnehumng und Akkulturationseffekte. In: Stern, Frank; Eichinger, Barbara. Wien und die jüdische Erfahrung, 1900-1938. Wien, Köln, Weimar: Böhlau. p.39-58. 2009.

LIMA, José Pedro de Carvalho.

Contribuição ao estudo da vaccinotherapia na coqueluche. Tese apresentada à Faculdade de Medicina do Rio de Janeiro, Rio de Janeiro. 1917.

LÖWY, Ilana.

Biotherapies of chronic diseases in the inter-war period: from Witte's peptone to Penicillium extract. Studies in History, Philosophy of Biological and Biomedical Sciences, Leeds, v.36, p.675-695. 2005.

MAZUMDAR, Pauline M. H.

Species and specificity: an interpretation of the history of immunology. Cambridge: Cambridge University Press. 1995. 
MORAES, María Inés.

Crescimento, tecnologia y competitividade em la ganadería uruguaia entre 1870-1930. In: Heinz, Flávio M., Herrlein Jr., Ronaldo. (Org.). Histórias regionais do Cone Sul. Santa Cruz do Sul: EdUnisc. p.269-292. 2003.

MOULIN, Anne Marie.

Patriarchal science: the network of the Overseas Pasteur Institutes. In: Petitjean, Patrick; Jami, Catherine; Moulinn, Anne Marie. Science and empires: historical studies about scientific development and European expansion. Dordrecht: Klumer. p.307-322. 1992.

NEIVA, Arthur.

Carta a Oswaldo Gonçalves Cruz. Buenos Aires. Fundo Oswaldo Cruz. Série Correspondência, BR RJCOC OC-COR. (Departamento de Arquivo e Documentação/Casa de Oswaldo Cruz/Fiocruz, Rio de Janeiro). 19 maio 1916.

\section{ÖFFENTLICHE VORLESUNGEN...}

Öffentliche Vorlesungen an der Universität zu Wien: Wintersemester 1901-1912. Wien: Adolf Holzhausen, K. und K. Hof- und Universitätsbuchdrucker.

PAGANI-CESA, Andrea.

A vaccinotherapia da coqueluche, seu valor curativo ou preventivo. Novotherapia, São Paulo, v.5, n.26, p.20-32. 1925.

PASCHOAL JÚNIOR, José Felix.

Coqueluche. Tese apresentada à Faculdade de Medicina do Rio de Janeiro, Rio de Janeiro. 1921.

PENNA, José; BONORINO CUENCA, Juan. Tratamiento de la coqueluche por la vacuna anticoqueluchosa del Dr. Kraus. Revista da Asociación Médica Argentina, Buenos Aires, v.23, p.1390-1394. 1915.

PENNA, José; BONORINO CUENCA, Juan; KRAUS, Rudolf.

El tratamiento del carbunculo humano con el suero normal de bovino. Revista del Instituto Bacteriológico del Departamento Nacional de Higiene, Buenos Aires, v.2, n.1, p.89-97. 1919.

RIBEIRO, Maria Alice Rosa.

Lições para a história das ciências no Brasil: Instituto Pasteur de São Paulo. História, Ciências, Saúde - Manguinhos, Rio de Janeiro, v.3, n.3, p.467-484. 1997.

\section{RUDOLF KRAUS.}

Rudolf Kraus. Medizinischer Personalakt. Wien. Haus, Hof und Staatsarchiv. AT-OeStA/HHStA MdÄ AR F36-31. MED PA 286-Rudolf Kraus. (Österreichisches Staatsarchiv). s.d.

SARASIN, Phillip et al.

Eine Einleitung. In: Sarasin, Phillip et al. Bakteriologie und die Moderne: Studien zur Biopolitik des Unsichtbaren. Frankfurt am Main: Suhrkamp. p.8-43. 2007.

SÔROS...

Sôros e vaccinas, produtos opotherápicos, chimiotherápicos, vitaminicos e diagnosticos. São Paulo: J. N. Poli. 1931.

SOUZA-ARAUJO, Heraclídes Cesar de. Professor Rodolpho Kraus. Revista Médico Cirúrgica do Brasil, Rio de Janeiro, v.40, n.8, p.238-243. 1932

SPECIAL CORRESPONDENCE.

Special correspondence: appointment of Professor Kraus to Buenos Aires. British Medical Journal, Londres, v.1, n.2731, p.969. 1913.

STANICK, Marco Antonio. Coqueluche: interpretações, controvérsias, e terapêuticas, 1850-1950. eä, Buenos Aires,v.2, n.1, p.1-28. Disponível em: http://www.eajournal.com.br. Acesso em: 9 ago. 2012. 2010.

TAUBER, I. Alfred; CHERNYAK, Leon. Metchnikoff and its origins of immunology: from metaphor to theory. Oxford: Oxford University Press. 1991.

TEICHMANN, Josef.

Zum 100. Geburtstag Rudolf Kraus. Wiener medizinische Wochenschrift, Viena, v.118, n.42, p.2-5. 1968.

TEICHMANN, Josef.

Bundestaatliche Serotherapeutisches Institut Wien. 1894-1954.Wien: Gustav Gruber. 1954.

TEIXEIRA, Luiz Antonio.

Ciência e saúde na terra dos bandeirantes: a trajetória do Instituto Pasteur de São Paulo no período de 1903-1916. Rio de Janeiro: Fiocruz. 1994.

THROM, Carola.

Behrings Vermarktung seiner Entdeckung. In: Throm, Carola. Das Diphtherieserum: Ein neues Therapieprinzip, seine Entwicklung und Markteinführung. Stuttgart: Wissenschaft Verlagsgesellschaft. p.47-81. 1995.

WEICHARDT, Wolfgang.

Über Proteinkörpertherapia. Münchener medizinische Wochenschrift, Munique, v.65, n.22, p.581-585. 1918.

WORBOYS, Michael.

Vaccine therapy and laboratory medicine in Edwardian Britain. In: Pickstone, John V. Medical innovations in historical perspective. London: Macmillian. p.84-103. 1992. 